\title{
Influence of Mould Wall Temperature and Content of Recycled Material on Shrinkage of Polymeric Part
}

\author{
Matija HRŽAN, Mladen ŠERCER
}

\begin{abstract}
Determination of optimal injection moulding parameters has significant impact on properties of a part. Usage of recycled material in process of injection moulding reduces costs of manufacturing but also alters properties of the part. This paper shows manufacturing process of test samples according to design of experiment, measuring of samples and statistic analysis of results in software Minitab. During trials influence of mould cavity wall temperature and content of recycled material on shrinkage will be investigated and analyzed. Content of recycled material that can be used for production of polymer part has direct influence on costs of production and the goal is to use maximal possible content of recycled material without affecting the shrinkage, respectively dimensions of part. Mathematical model that predicts final dimension of part in regard to input parameters will be set.
\end{abstract}

Keywords: content of recycled material; injection moulding; mould wall temperature; shrinkage

\section{INTRODUCTION}

Today's changes on global markets require that companies adjust to new challenges. Continuous reduction of costs is needed in order to remain competitive on market, keep existing customers and win new markets. This need for more rational use of recourses has led to development of new polymer materials but also to recycling of materials. Recycling is a name for "reusing of material" so "recycling of plastic" means reusing of plastic waste [1-6].

For analysis done in this paper methodology of design of experiments will be applied. An experiment is a test or series of tests where the experimenter makes purposeful changes to input variables of a process or a system so that the effects on the output variables can be observed and identified. Design of experiments (DOE) is concerned with the planning and conduct of experiments to analyze the resulting data so that valid and objective conclusions can be obtained [2].

The goal of analysis is to determine if and in what measure factors that are analysed have an impact on shrinkage of polymer part during cooling. Shrinkage on the other hand directly influences dimensions of polymer part respectively difference between nominal value on drawing and actual dimension measured on part. Definition of shrinkage of polymer material was very well defined by Fischer in "Handbook of moulded part shrinkage and warpage": Mould shrinkage (in-mould shrinkage or moulded-part shrinkage are more accurate terms), although a volume phenomenon, usually refers to the difference between the linear dimension of some part of the mould at room temperature and that of the same part of the moulded part at room temperature and about $48 \mathrm{~h}$ following ejection [7]. Influence of injection moulding parameters on shrinkage of polymer parts has been in the focus of researchers for some time now. Jensen et al. made complete study of seven most common polymer materials in order to investigate influence of injection moulding parameters on shrinkage. It was concluded that holding pressure has the highest influence on shrinkage [8]. Kusić and Hančič et al. also researched influence of injection moulding parameters on shrinkage and it was concluded that from six monitored parameters holding pressure has the highest influence on shrinkage [9]. However holding pressure and holding pressure time also influence total weight of part. With higher holding pressure material will be packed to a higher level and therefore more material will be used. As a consequence in a mass production this will increase total costs of parts since for the same quantity of parts more material has to be used. In this paper the goal will be to determine in which way other factors, specifically mold wall temperature and content of recycled material, influence shrinkage. Shrinkage of material except dimensional deviations as a consequence can have appearance of sink marks and voids on part surface especially on places with thicker wall thickness (opposite to and adjoining a leg or a rib). This occurs because of unbalanced heat removal or similar factors [10].

Amount of shrinkage is also affected by type of polymer selected. Thermoplastic polymers can be divided into two distinct types:

- amorphous

- $\quad$ semi-crystalline polymers.

In general shrinkage rate of crystalline polymers is greater than those of amorphous ones [11].

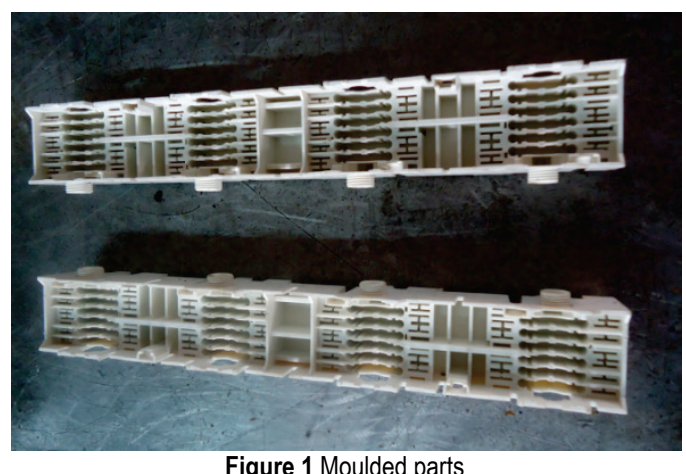

\section{ANALYSIS OF INFLUENCE OF RECYCLED MATERIAL CONTENT AND MOULD WALL TEMPERATURE ON SHRINKAGE}

\subsection{Selection of Polymer Part}

Test samples needed for the research will be manufactured in existing mould marked as 41.830.xx. Fig. 
1 shows moulded parts. Used mould has two mould cavities.

Dimension that will be analysed is shown in Fig. 2.

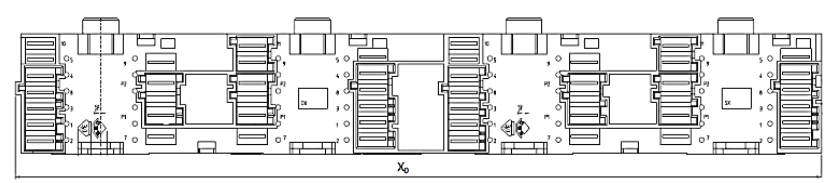

Figure 2 Sketch of part with analysed dimension

Dimension which will be analysed is $X_{0}$ - Length of polymer part $(\mathrm{mm})$. Targeted value is $X_{0}=262,3 \mathrm{~mm}$. Length of dimension that defines $X_{0}$ in mold cavity on room temperature is $X_{\mathrm{m}}=263,1 \mathrm{~mm}$.

\subsection{Selection of Polymer Material}

Taromid A280 H G6 DX0 TR1 S01 was used as polymer material for the research. Material is polyamide PA66 strengthened with $30 \%$ of glass fibres. It is in compliance with UL94 V0. Material has high mechanical properties and is heat resistant. It has low shrinkage and high dimensional stability [12].

The goal of research is to determine influence of mould wall temperature and content of recycled material on shrinkage of the part during the process of injection moulding.

The main advantage of the use of recycled material is reduction of production costs caused by lower consumption of virgin material. The main reason why sometimes it is not possible to use recycled material is that it can lead to decline of mechanical and electrical properties but also to the change in shrinkage of the part.

\subsection{Design of Experiment (DOE)}

Higher order design of experiment is chosen according to Response Surface Methodology (RSM). Chosen design of experiment is called Central Composite Design (CCD). This type of DOE is most common in response surface methodology [13].

First factor that will be researched is mould wall temperature $T_{k}$. Mould wall temperature will be changed in interval between $75^{\circ} \mathrm{C}$ and $120^{\circ} \mathrm{C}$.

Second researched factor will be content of recycled material in virgin material. Content of recycled material will be changed in the range from $0 \%$ to $100 \%$. These two factors were chosen to see if it is possible to determine optimal mould temperature in order to compensate for the changes caused by mixing of recycled material with virgin one during production of test samples.

Chosen factors are shown in Tab. 1. Design of experiment which requires 39 samples to be produced was created in software package Minitab. DOE with 39 repetitions was chosen for precision. Design of experiment is shown in Tab. 2.

Table 1 Factors and ranges

\begin{tabular}{|c|c|c|}
\hline Levels & $\begin{array}{c}\text { A-Mould wall } \\
\text { temperature }\left({ }^{\circ} \mathrm{C}\right)\end{array}$ & $\begin{array}{c}\mathrm{B}-\text { Content of recycled } \\
\text { material }(\%)\end{array}$ \\
\hline-1 & 75 & 0 \\
\hline 0 & 97,5 & 50 \\
\hline 1 & 120 & 100 \\
\hline
\end{tabular}

Table 2 Design of experiment

\begin{tabular}{|c|c|c|c|}
\hline $\begin{array}{l}\text { Standard } \\
\text { order }\end{array}$ & $\begin{array}{c}\text { Order of } \\
\text { manufacturing }\end{array}$ & $\begin{array}{c}\text { Mould wall } \\
\text { temperature }\left({ }^{\circ} \mathrm{C}\right)\end{array}$ & $\begin{array}{c}\text { Content of } \\
\text { recycled } \\
\text { material }(\%)\end{array}$ \\
\hline 28 & 1 & 113,4 & 14,6 \\
\hline 35 & 2 & 97,5 & 50 \\
\hline 34 & 3 & 97,5 & 100 \\
\hline 39 & 4 & 97,5 & 50 \\
\hline 27 & 5 & 81,6 & 14,6 \\
\hline 33 & 6 & 97,5 & 0 \\
\hline 29 & 7 & 81,6 & 85,4 \\
\hline 32 & 8 & 120 & 50 \\
\hline 37 & 9 & 97,5 & 50 \\
\hline 31 & 10 & 75 & 50 \\
\hline 30 & 11 & 113,4 & 85,4 \\
\hline 38 & 12 & 97,5 & 50 \\
\hline 36 & 13 & 97,5 & 50 \\
\hline 1 & 14 & 81,6 & 14,6 \\
\hline 7 & 15 & 97,5 & 0 \\
\hline 11 & 16 & 97,5 & 50 \\
\hline 8 & 17 & 97,5 & 100 \\
\hline 10 & 18 & 97,5 & 50 \\
\hline 4 & 19 & 113,4 & 85,4 \\
\hline 13 & 20 & 97,5 & 50 \\
\hline 2 & 21 & 113,4 & 14,6 \\
\hline 3 & 22 & 81,6 & 85,4 \\
\hline 12 & 23 & 97,5 & 50 \\
\hline 9 & 24 & 97,5 & 50 \\
\hline 5 & 25 & 75 & 50 \\
\hline 6 & 26 & 120 & 50 \\
\hline 15 & 27 & 113,4 & 14,6 \\
\hline 24 & 28 & 97,5 & 50 \\
\hline 18 & 29 & 75 & 50 \\
\hline 26 & 30 & 97,5 & 50 \\
\hline 16 & 31 & 81,6 & 85,4 \\
\hline 14 & 32 & 81,6 & 14,6 \\
\hline 22 & 33 & 97,5 & 50 \\
\hline 23 & 34 & 97,5 & 50 \\
\hline 19 & 35 & 120 & 50 \\
\hline 17 & 36 & 113,4 & 85,4 \\
\hline 25 & 37 & 97,5 & 50 \\
\hline 21 & 38 & 97,5 & 100 \\
\hline 20 & 39 & 97,5 & 0 \\
\hline
\end{tabular}

\subsection{Manufacturing of Test Samples and Measurement}

Test samples were manufactured according to design of experiments on the following equipment:

- Injection moulding machine: Arburg Allrounder 570C 2200-800 [15] - clamping force $2200 \mathrm{kN}$, screw diameter $45 \mathrm{~mm}$, material throughput $23 \mathrm{~kg} / \mathrm{h}$ PA 6.6 [14]

- Mould: 41.830.xx

- Device for tempering of mould wall: Regloplas 300S [17] - 2 pieces - heating capacity $6 \mathrm{~kW}$, cooling capacity $70 \mathrm{~kW}$, max flow 45,42 1/min [14]

- Drying device: Arburg Thermolift 100-2 [15]

- Temperature measuring device: Hasco Z251/2

After the parts were produced they were left for 48 hours before measuring. After 48 hours response variables ( $X_{s}$ - Lengths of samples) were measured. Statistical analysis of measurements was done in software Minitab. Analysis results are shown in Tab. 3.

Regression equation that describes model is the following:

$X_{s}=263,454-0,011483 \cdot T_{k}-0,002567 \cdot U_{r}$

$X_{s}$ - Length of polymer sample (mm) 
$T_{k}$ - Mould wall temperature $\left({ }^{\circ} \mathrm{C}\right)$

$U_{r}$ - Content of recycled material (\%)

Table 3 Results of statistical analysis

\begin{tabular}{|c|c|c|c|c|c|}
\hline Source & $D F$ & Adj $S S$ & Adj $M S$ & F-Value & P-Value \\
\hline Model & 4 & 1,05487 & 0,263718 & 88,0 & 0,000 \\
\hline Blocks & 2 & 0,05625 & 0,028126 & 9,39 & 0,001 \\
\hline Linear & 2 & 0,99862 & 0,499310 & 166,62 & 0,000 \\
\hline $\begin{array}{c}\text { Mould wall } \\
\text { temperature }\end{array}$ & 1 & 0,80098 & 0,800978 & 267,29 & 0,000 \\
\hline $\begin{array}{c}\text { Content of } \\
\text { recycled } \\
\text { material }\end{array}$ & 1 & 0,19764 & 0,197642 & 65,95 & 0,000 \\
\hline Error & 34 & 0,10189 & 0,002997 & & \\
\hline Lack-of-Fit & 22 & 0,07729 & 0,003513 & 1,71 & 0,168 \\
\hline Pure Error & 12 & 0,02460 & 0,002050 & & \\
\hline Total & 38 & 1,15676 & & & \\
\hline
\end{tabular}

Model summary is shown in Tab. 4.

\begin{tabular}{|c|c|c|c|} 
Table 4 Model summary \\
\begin{tabular}{|c|c|c|c|}
\hline$S$ & $R-s q$ & $R$-sq (adj) & $R$-sq(pred) \\
\hline 0,0547420 & $91,19 \%$ & $90,16 \%$ & $88,05 \%$ \\
\hline
\end{tabular}
\end{tabular}

Corelation between "response value" [ $\mathrm{mm}$ ] and factors "content of recycled material" [\%] and "mold wall temperature" [ $\left.{ }^{\circ} \mathrm{C}\right]$

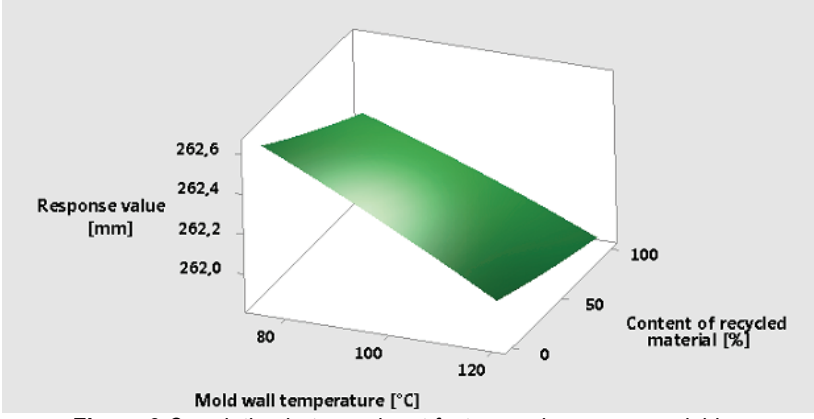

Figure 3 Correlation between input factors and response variable

\section{RESULTS AND DISCUSSION}

Analysis of variance has shown that both factors are significant because the risk for rejection of factor is 0,05 while for both factors the value of $\mathrm{p}$ is below threshold of 0,05 . Also, the value $F$ for model is 88 which suggests that the model is significant. From acquired data it can be concluded that model describes experiment results very well. Tab. 4 shows determination coefficient which is equal to $88,05 \%$, so it can be concluded that regression equation is representative. Based on regression equation it is possible to predict final dimensions of test samples produced from PA66 if values of input factors are known (mould wall temperature and content of recycled material in virgin material). Fig. 3 shows the surface that describes correlation of response variable (length of sample) and two input factors - mould wall temperature and content of recycled material. Analysis has shown that increase in mould wall temperature as result has higher shrinkage because response variable (total length of sample) is smaller. With lower mould wall temperatures shrinkage is lower as it can be seen in Fig. 4 and respectively response variable (total length of part) is larger as shown in Fig. 3. These results were expected because crystallized polymers like PA66 with increase of mould wall temperature as a consequence have higher degree of crystallinity. With higher degree of crystallinity structure of final part is in higher level of order which means bigger difference between specific volume of melted and solid phase. Also, analysis has shown that with increased content of recycled material in virgin material shrinkage is higher and respectively response variable (total length) is smaller. When content of recycled material in virgin material is reduced shrinkage is lower as it can be seen in figure 4 and respectively response variable (total length of part) is larger as shown in Fig. 3.

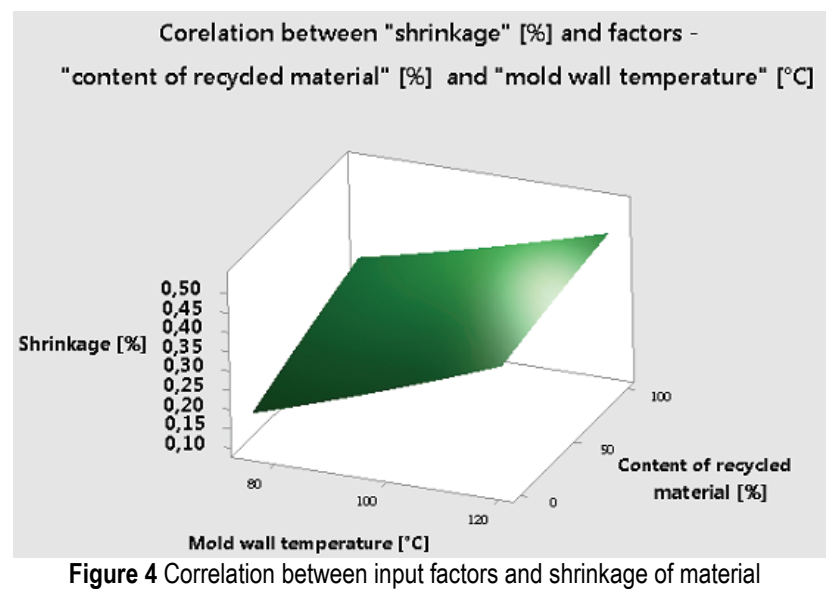

Based on the results of analysis it is possible to predict shrinkage of material caused by change in content of recycled material and compensate for it by adjusting the mould wall temperature. This enables that shrinkage level remains constant but at the same time higher content of recycled material can be used. Higher content of recycled material has positive effect on cost reduction and production profitability since less of virgin material has to be used for production of parts.

\section{CONCLUSION}

Analysis conducted based on design of experiment has shown that both content of recycled material and mould wall temperature influence shrinkage of polymer product when it is produced from reinforced crystalline thermoplastic such as PA66 with 30\% of glass fibres. When recycled material is used for production of parts it is crucial to properly determine content of recycled material in virgin material because with changes in content of recycled material shrinkage will be changed. With change in shrinkage, length and other dimensions of part will also change. It is possible to make mathematical model shown in Eq. (1) which can predict output variable respectively total length of polymer part based on input factors in form of data concerning mould wall temperature and content of recycled material which are known. For future it is planned to also investigate the influence of observed parameters on unreinforced crystalline thermoplastic and amorphous thermoplastic.

\section{REFERENCES}

[1] Šercer, M., Opsenica, D., \& Barić, G. (2000). Oporaba plastike i gume, Mtg-topgraf, Zagreb.

[2] Bross, P. J. (2006). Design of Experiments, https://www.scribd.com/document/105124377/Design-ofExperiments/. (01.03.2017). 
[3] Borojevic, S., Lukic, D., Milosevic, M., Vukman, J., \& Kramar, D. (2018). Optimization of process parameters for machining of Al 7075 thin-walled structures. Advances in Production Engineering \& Management, 13(2), 125-135. https://doi.org/10.14743/apem2018.2.278

[4] Boyacı, A. İ., Hatipoğlu, T., \& Balcı, E. (2017). Drilling process optimization by using fuzzy-based multi-response surface methodology. Advances in Production Engineering \& Management, 12(2), 163-172. https://doi.org/10.14743/apem2017.2.248

[5] Lerher, T., Borovinsek, M., Ficko, M., \& Palcic I. (2017). Parametric Study of Throughput Performance in SBS/RS Based on Simulation. International Journal of Simulation Modelling, 16(1), 96-107. https://doi.org/10.2507/IJSIMM16(1)8.372

[6] Simunovic, G., Svalina, I., Simunovic, K., Saric, T., Havrlisan, S., \& Vukelic, D. (2016). Surface roughness assessing based on digital image features. Advances in Production Engineering \& Management, 11(2), 93-104. https://doi.org/10.14743/apem2016.2.212

[7] Fischer, J. M. Handbook of Moulded Part Shrinkage and Warpage - Determination of Shrinkage; Beckley, B., Ed., Plastics Design Library=William Andrew Pub.: Norwich, NY, 2003. ISBN: 978-1-4557-2597-7.

[8] Jansen, K. M. B., Van Dijk, D. J., \& Husselman, M. H. (1998). Effect of processing conditions on shrinkage in injection moulding, 838-846. https://doi.org/10.1002/pen.10249

[9] Kusić, D. \& Hančič, A. (2015). Influence of moulding conditions on the shrinkage and warpage behaviour of standardized test specimens, Proceedings of the Regional Conference - Polymer Processing Society PPS, Graz. https://doi.org/10.1063/1.4965468

[10] Anonymous. Shrinkage and Warpage, http://www.dc.engr.scu.edu/cmdoc/dg_doc/develop/trouble/ sinkmark/f5000001.htm (accessed November 2016)

[11] Anonymous. Industry know-how, http://www.plastribution.co.uk/wpcontent/uploads/2014/04/ Shrinkage-Industry_know-how.pdf (accessed June 2017)

[12] Manufacturers data Taroplast; Taromid A, http://www.taroplast.com/en/Prodotto/4/taromida/ (accessed June 2017)

[13] Cajner H. Višekriterijsko adaptivno oblikovanje planova pokusa, Doktorski rad, 2011. UDK: 519.242. (in Croatian)

[14] Arburg equipment catalog, https://www.arburg.com/ fileadmin/redaktion/Mediathek/Technische_Daten/ARBUR G_ALLROUNDER_570S_TD_680126_en_GB.pdf2016 (accessed June 2017)

[15] Regloplasequipment catalog, http://www.regloplasusa.com/ us/ProductDetails.aspx?prdtName $=$ Product_300S\&path $=/ \mathrm{P}$ roduct_300S\&view=TechData (accessed June 2017)

\section{Contact information:}

Matija HRŽAN, mag. ing. mech.

Corresponding author

Elektro-kontakt d.d.,

Radnička cesta 115, 10000 Zagreb, Croatia

E-mail: matija.hrzan@egoproducts.com

Mladen ŠERCER, prof. dr. sc

Fakultet strojarstva i brodogradnje,

Sveučilišta u Zagrebu,

Ivana Lučića 5, 10000 Zagreb, Croatia

E-mail: mladen.sercer@fsb.hr 